Article

\title{
Experimental Study on Mechanical Properties, Failure Behavior and Energy Evolution of Different Coal-Rock Combined Specimens
}

\author{
Shang Yang, Jun Wang * ${ }^{\mathbb{D}}$, Jianguo Ning and Pengqi Qiu \\ State Key Laboratory of Mining Disaster Prevention and Control, Shandong University of Science \\ and Technology, Qingdao 266590, China; yangshang0214@126.com (S.Y.); njglxh@126.com (J.N.); \\ qiupengqi@126.com (P.Q.) \\ * Correspondence: jwangmining@sdust.edu.cn
}

Received: 16 August 2019; Accepted: 13 October 2019; Published: 18 October 2019

check for updates

\begin{abstract}
To investigate the effect of the pure coal/rock strength on the mechanical behavior, failure behavior, and energy evolution of coal-rock combined (CRC) specimens, an AG-X250 Shimadzu Precision Universal Test was used to conduct uniaxial compressive loading, uniaxial cyclic loading, and unloading compression experiments on pure coal, pure rock, and different CRC specimens. The results show that the uniaxial compressive strength, Young's modulus, and peak strain of the CRC specimen mainly depend on the coal specimen instead of the rock strength. The major failure modes of CRC were the shearing fracture and axial splitting failure, and for the CRC specimen with the same hard rock, the CRC specimen severely failed due to axial splitting cracks. In addition, the released elastic energy $U_{\mathrm{e}}$, dissipated energy $U_{\mathrm{d}}$, and kinetic energy $U_{r}$ increase with increasing rock mass/coal strength, and for CRC specimen with the same coal, the greater the difference in strength between the rock and coal is, the greater the kinetic energy is.
\end{abstract}

Keywords: coal-rock combined specimen; uniaxial compressive loading; uniaxial cyclic loading and unloading compression; energy

\section{Introduction}

In underground coal mines, coal pillars are often used for the purpose of ground control [1,2]. During the process of mining, coal pillar instability is often encountered [3]. Many researchers have reported that coal pillar instability is the product of destruction of coal-rock masses under high stress [4,5]. Practices showed that the coal pillar instability is affected not only by their internal cracks and joints, but also by the strength of the roof and floor [6]. It is necessary to study the mechanical properties and failure behavior of the system composed of roof/floor rocks and coal.

Coal and rock mass failure is a long-standing issue, and its mechanical properties and failure characteristics have been essential parameters for underground coal engineering, such as mining design, gateroad support design, etc. [7-10]. Numerous studies [11-17] have been carried out to study the mechanism of coal and rock mass failure by testing the pure coal/rock specimens. It has been shown that common types of coal and rock mass failure mechanism include tension failure, shear failure, and tension-shear failure. The above results provide a basis for understanding the instability of coal pillars. In fact, coal pillars are often left to support the overlying strata in underground engineering, and then the coal, roof and floor bear loads together [18]. Thus, it can be expected that the mechanical properties and failure behavior of underground coal and rock mass may different from that of pure coal/rock specimens. In other words, it is hard to understand the deformation and failure characteristics of underground construction in accordance with the experimental results of coal/rock specimens. 
Therefore, a kind of coal-rock combined (CRC) specimen was tested and its mechanical properties, and failure behavior were found to possibly be useful for forecasting the deformation and failure of the coal pillar. Generally, extensive studies have been conducted to understand the mechanical properties and failure behavior through the application of different methods, including numerical methods, laboratory experiments, and theoretical analysis [19-21]. Bai et al. [22] found that when the CRC specimen was loaded, AE (Acoustic Emission) events are more likely to be generated in the coal section, if damage first occurred in the coal section. Chen et al. [23] also suggested that the mechanical properties and deformation failure characteristics of the coal-rock combined body were governed mainly by the coal section. These studies indicated that the strength of a CRC specimen is not only affected by its mechanical properties, but also by other parameters such as the properties of coal-rock interfaces and the interface dipping angle. A literature review showed that the effects of the coal/rock strength on the mechanical behavior and failure mode of the CRC specimen is still unclear, since the mechanical behavior of the CRC specimen is more prominent than that of pure coal/rock specimens.

Since Cook [24] first pointed out the link between excess strain energy and the damage due to strainbursts, an increasing number of studies have been performed to understand the energy evolution during coal and rock mass failure. Xie et al. [25] and Peng et al. [26] point that from the perspective of energy in the energy transformation, coal and rock mass failure is energy-driven instability that includes energy absorption, evolution, and dissipation. Bagde and Petros [27] studied rock energy characteristics under dynamic cyclic loading, and found that higher rock strength leads to greater energy absorption. Conducting compression tests on bedded-sandstone with bedding layers in different orientations, Wasantha et al. [28] found that for rock with bedding layers inclined in shallow angles failures, energy release could be more violent than failures of rock with steeply oriented bedding layers. These studies implied that the energy absorption, release of coal, and rock mass failure was dependent on rock type, geological structures, etc. Liu et al. [29] point that CRC specimen failure depends on energy release and strain energy was converted into kinetic energy through initiation, propagation, and coalescence of micro-fractures until the final instability occurred. Tan et al. [30] suggested that energy release of the CRC specimen was in connection with the lithology. Limited literature on the effects of the coal/rock strength on the energy evolution of CRC specimens is available. This is partly because coal developed in rock strata, including limestone, mudstone, and siltstone generally has relatively weak mechanical properties compared to in marble or granite. Hence, specimen preparation is hard to achieve.

Therefore, the authors prepared standard CRC specimens of different pure coal and pure rock specimens to conduct uniaxial compression, uniaxial cyclic loading, and unloading tests on the pure rock specimens, pure coal specimens and different CRC specimens. To understand the mechanical properties, failure behavior, and energy evolution of different CRC specimens. Then, influence of the coal/rock strength on the mechanical behavior, failure mode and energy evolution of the CRC specimen was discussed.

\section{Testing Program}

\subsection{Specimen Preparation and Descriptions}

Four types of rock specimens (mudstone, siltstone, fine sandstone, and medium sandstone) and two types of coal specimens were utilized. The mudstone, siltstone, fine sandstone, and medium sandstone specimens were extracted from the roof of the No. 3 coal seam in the Xinhe coal mine, Jining City, Shandong Province, in Northern China. One type of coal specimen was also taken from the No. 3 coal seam in the Xinhe coal mine (named $\mathrm{M}_{1}$ in the following section), and another type was taken from the No. 2-2-medium coal seam from the Gaojialiang coal mine, Inner Mongolia, China (named $\mathrm{M}_{2}$ in the following section). The natural specimens obtained on the site were stored in the laboratory with a plastic film for no longer than 30 days to preserve their natural water content. The siltstone and fine sandstone specimens were even textured, and the values of the siltstone and fine sandstone rock quality designation (RQD) were approximately $89 \%$ and $76 \%$, respectively. The medium sandstone 
was locally interbedded with thin beds of siltstone with an RQD of $66 \%$, while the mudstone specimens locally contained clasts of plant fossils with an RQD of $45 \%$. The coal specimens taken from the Xinhe coal mine were simple in structure with high strength, while coal specimens taken from the Gaojialiang coal mine had a low uniaxial compressive strength. The bulk density of the coal specimens varied in a small range from 1.56 to $1.65 \mathrm{~g} / \mathrm{cm}^{3}$. The representative porosity of the specimens was $18.6 \%$.

The specimens were processed into standard cylinders with diameters of $50 \mathrm{~mm}$, and the height of the cylinders was also $50 \mathrm{~mm}$. According to the standard suggested by the International Society for Rock Mechanics (ISRM), the specimens were polished to make both ends parallel and smooth. There were four types of rock specimens and two types of coal specimens. Following the method suggested by Liu et al. [31], one coal specimen of $\Phi 50 \mathrm{~mm} \times 50 \mathrm{~mm}$ and one rock specimen of $\Phi 50 \mathrm{~mm} \times 50 \mathrm{~mm}$ were glued together to make a CRC specimen with a height of $100 \mathrm{~mm}$. Then, there were eight types of CRC specimens, and a total of 40 specimens were prepared. The specimen numbers used in testing are listed in Table 1.

Table 1. The lithology and size of the specimens.

\begin{tabular}{ccc}
\hline Specimen Label & Lithology & Rock-Coal Height (mm) \\
\hline $\mathrm{M}_{1}-1,2,3$ & $\# 1$ coal & $0-100$ \\
$\mathrm{M}_{2}-1,2,3$ & $\# 2$ coal & $0-100$ \\
$\mathrm{NY}-1,2,3$ & Mudstone & $100-0$ \\
$\mathrm{XS}-1,2,3$ & Fine sandstone & $100-0$ \\
$\mathrm{ZS}-1,2,3$ & Medium sandstone & $100-0$ \\
$\mathrm{FS}-1,2,3$ & Siltstone & $100-0$ \\
$\mathrm{NYM}_{1}-1,2,3,4,5$ & Mudstone+\#1 coal & $50-50$ \\
$\mathrm{NYM}_{2}-1,2,6,7,8$ & Mudstone+\#2 coal & $50-50$ \\
$\mathrm{XSM}_{1}-1,2,3,4,5$ & Fine sandstone+\#1 coal & $50-50$ \\
$\mathrm{XSM}_{2}-1,2,6,7,8$ & Fine sandstone+\#2 coal & $50-50$ \\
$\mathrm{ZSM}_{1}-1,2,3,4,5$ & Medium sandstone sandstone+\#1 coal & $50-50$ \\
$\mathrm{ZSM}_{2}-1,2,6,7,8$ & Medium sandstone sandstone+\#2 coal & $50-50$ \\
$\mathrm{FSM}_{1}-1,2,3,4,5$ & Siltstone+\#1 coal & $50-50$ \\
$\mathrm{FSM}_{2}-1,2,6,7,8$ & Siltstone+\#2 coal & $50-50$ \\
\hline
\end{tabular}

\subsection{Testing Apparatus and Testing Program}

Two types of laboratory tests were conducted: uniaxial compressive loading, uniaxial cyclic loading and unloading compression. These tests were carried out using the AG-X250 Shimadzu Precision Universal Test with a maximum load capacity of $250 \mathrm{kN}$ (Figure 1). All the CRC specimens were tested under uniaxial cyclic loading and unloading compression, and the pure rock/coal specimens were tested under uniaxial compressive loading, as listed in Figure 2.

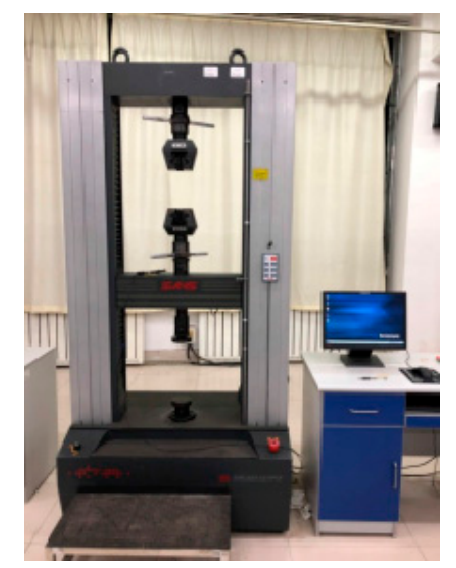

Figure 1. The AG-X250 Shimadzu Precision Universal Test. 

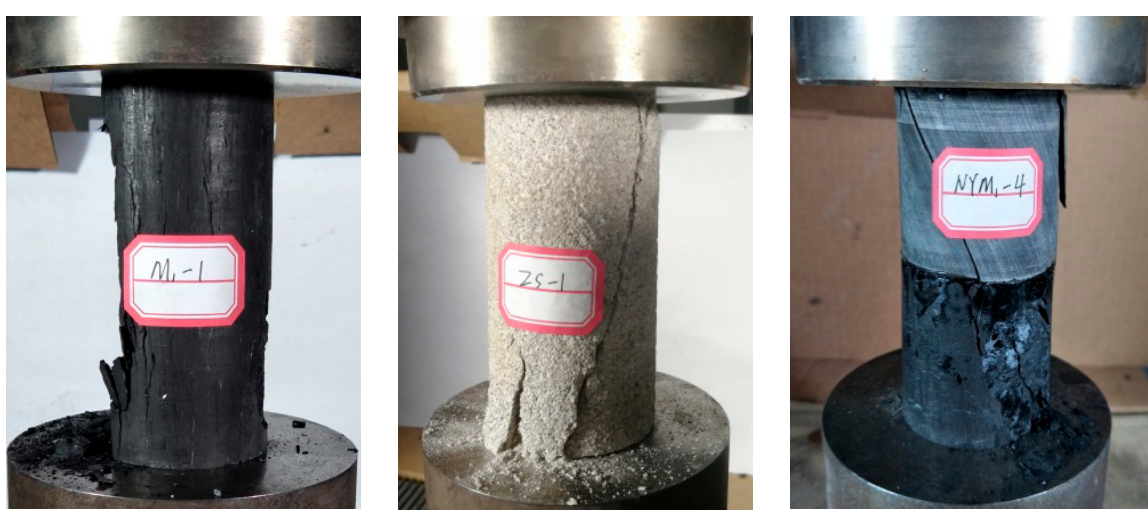

Figure 2. Test process of the specimens.

The uniaxial compression loading adopted a displacement-controlled mode with the loading rate of $0.001 \mathrm{~mm} / \mathrm{s}$. Three specimens of the same size were tested under uniaxial cyclic loading and unloading compression with displacement-controlled mode occurred. Each specimen was continuously loaded and unloaded until failure occurred, i.e., $0 \mathrm{KN} \rightarrow 6 \mathrm{KN} \rightarrow 0.5 \mathrm{KN} \rightarrow 12 \mathrm{KN} \rightarrow 0.5 \mathrm{KN} \rightarrow 18 \mathrm{KN} \rightarrow \ldots$ $\ldots \rightarrow$ failure. It should be pointed out that both the loading and unloading rate was $0.001 \mathrm{~mm} / \mathrm{s}$.

\section{Experimental Results}

\subsection{Stress-Strain Curve under Uniaxial Compressive Loading}

In each uniaxial compression test, uniaxial stress and strain were obtained and the determination of uniaxial stress and strain was carried out using the method suggested by ISRM [32]. Typical stress-strain curves of the coal, rock, and CRC specimens are shown in Figure 3.

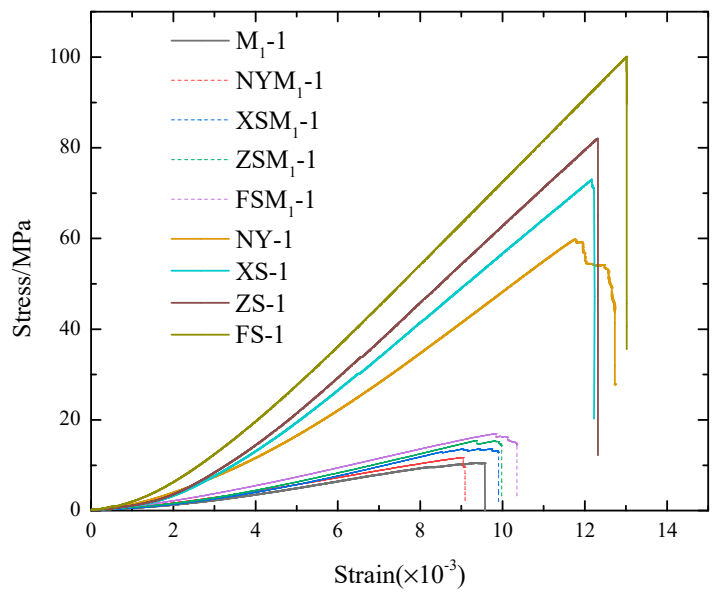

(a)

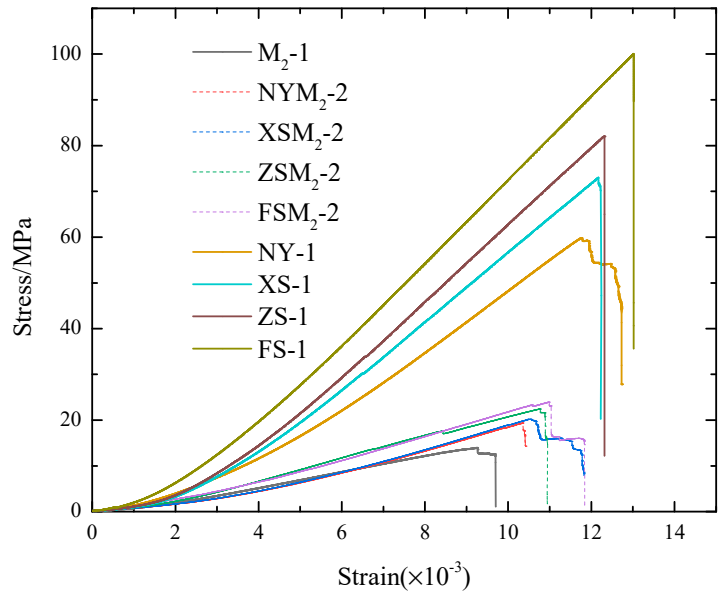

(b)

Figure 3. Typical stress-strain curves of pure coal/rock and CRC specimens: (a)\#1 coal and (b) \#2 coal.

From Figure 3, it can be seen that the stress-strain curves of the CRC specimen under uniaxial compressive loading are similar to those of pure rock/coal specimens, which is in good agreement with the experimental results obtained by Liu et al. [33]. In all cases during the compressive test, the stress-strain curves of the CRC specimen showed nonlinear behavior in the initial deformation stage, which is usually attributed to crack closure. Following this period of crack closure, the CRC specimen exhibited elastic deformation (the stress-strain curves of this part are linear). When CRC specimens cannot bear the loading, the curves bent downwards prior to failure, where they entered a yield phase. Once the peak stress was reached, the CRC specimens began to break, and their ability to resist uniaxial loads dropped. 
It should be noted that because the pure rock specimen is a brittle material, only a small deformation leads to instability, and the yield stages in the stress-strain curves of the pure rock specimen are not easy to recognize. However, the yield stages in the curves of both the CRC specimen and the pure coal specimen are easy to recognize. Wang [34] suggested that throughout the yield point, AE events in rock material will increase dramatically, following a relatively quiet period. The time of the AE quiet period can be easily identified by the AE monitoring system, which could be used as the early-warning point of rock instability. According to the results presented by Wang, it can be deduced that the early-warning key points of the CRC specimen instability could be easily identified.

\subsection{Young's Modulus, Uniaxial Compressive Strength and Axial Strain at Peak Stress}

To observe the effects of rock/coal strength on the deformation behavior and strength of the CRC specimen, the Young's modulus, uniaxial compressive strength, and its corresponding uniaxial strain under uniaxial compressive loading were calculated. The effects of rock/coal strength on the Young's modulus, uniaxial compressive strength, and its corresponding axial strain in the CRC specimen are shown in Figures 4-6. The deformation parameters and peak compressive strength of the pure rock/coal specimens are listed in Table 2.

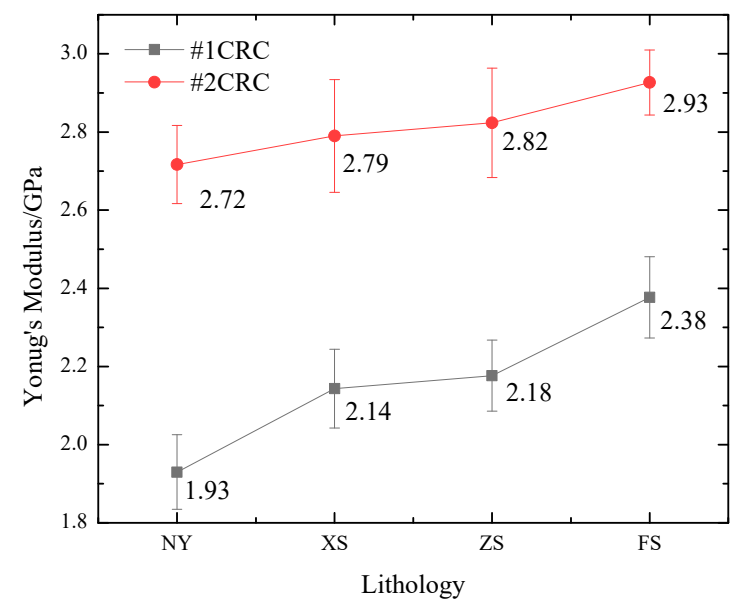

Figure 4. The Young's modulus of the coal-rock combined (CRC) specimens.

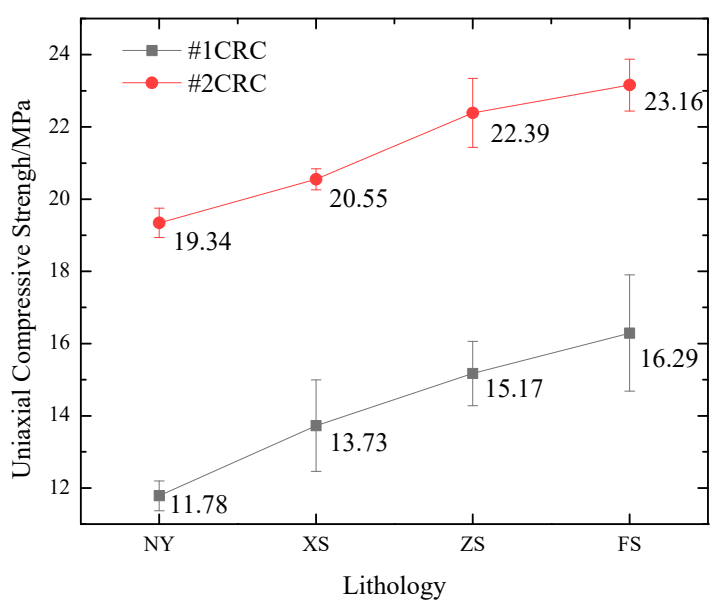

Figure 5. The compressive strength of the CRC specimens. 


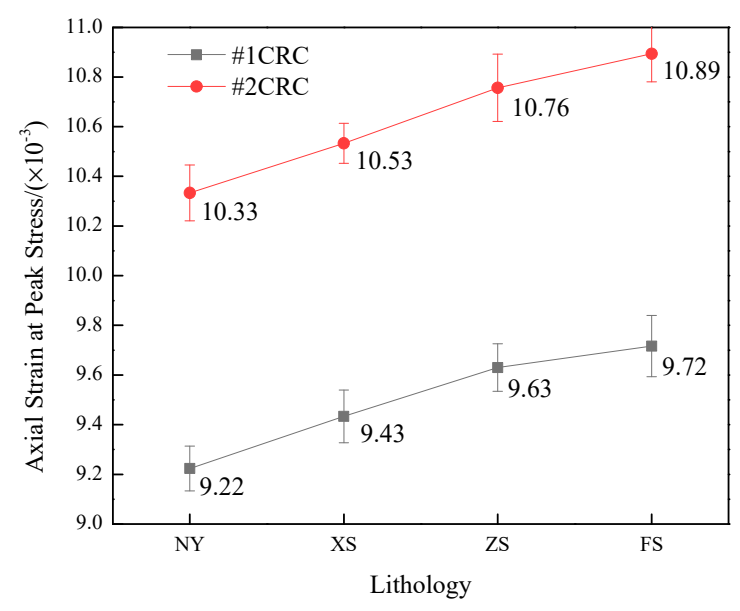

Figure 6. The axial strain at the peak stress of the CRC specimens.

Table 2. Young's modulus, uniaxial compressive strength and axial strain at peak stress of the pure coal/rock specimens.

\begin{tabular}{|c|c|c|c|c|c|c|c|}
\hline Group & $\begin{array}{c}\text { Specimen } \\
\text { Label }\end{array}$ & $\begin{array}{c}\text { Modulus/ } \\
\text { GPa }\end{array}$ & $\begin{array}{c}\text { Average/ } \\
\text { GPa }\end{array}$ & $\begin{array}{c}\text { Uniaxial } \\
\text { Compressive } \\
\text { Strength/MPa }\end{array}$ & $\begin{array}{c}\text { Average/ } \\
\text { MPa }\end{array}$ & $\begin{array}{l}\text { Axial Strain } \\
\text { at Peak Stress } \\
\quad\left(\times 10^{-3}\right)\end{array}$ & $\begin{array}{c}\text { Average } \\
\left(\times 10^{-3}\right)\end{array}$ \\
\hline \multirow{3}{*}{$\mathrm{M}_{1}$} & $\mathrm{M}_{1}-1$ & 1.23 & \multirow{3}{*}{1.4} & 8.8 & \multirow{3}{*}{10.53} & 9.28 & \multirow{3}{*}{9.39} \\
\hline & $\mathrm{M}_{1}-2$ & 1.52 & & 12.3 & & 9.52 & \\
\hline & $\mathrm{M}_{1}-3$ & 1.45 & & 10.5 & & 9.37 & \\
\hline \multirow{3}{*}{$\mathrm{M}_{2}$} & $\mathrm{M}_{2}-1$ & 1.72 & \multirow{3}{*}{1.75} & 14.1 & \multirow{3}{*}{14.3} & 9.26 & \multirow{3}{*}{9.26} \\
\hline & $\mathrm{M}_{2}-2$ & 1.58 & & 12.7 & & 9.20 & \\
\hline & $\mathrm{M}_{2}-3$ & 1.85 & & 16.2 & & 9.33 & \\
\hline \multirow{3}{*}{ NY } & NY-1 & 6.82 & \multirow{3}{*}{6.86} & 59.14 & \multirow{3}{*}{59.7} & 11.95 & \multirow{3}{*}{11.95} \\
\hline & NY-2 & 7.05 & & 62.32 & & 12.04 & \\
\hline & NY-3 & 6.75 & & 57.65 & & 11.87 & \\
\hline \multirow{3}{*}{ XS } & XS-1 & 7.54 & \multirow{3}{*}{7.51} & 73.01 & \multirow{3}{*}{72.67} & 12.17 & \multirow{3}{*}{12.16} \\
\hline & XS-2 & 7.32 & & 69.22 & & 12.06 & \\
\hline & XS-3 & 7.67 & & 75.78 & & 12.24 & \\
\hline \multirow{3}{*}{ ZS } & ZS-1 & 8.37 & \multirow{3}{*}{8.33} & 82.04 & \multirow{3}{*}{81.87} & 12.31 & \multirow{3}{*}{12.41} \\
\hline & ZS-2 & 8.11 & & 77.22 & & 12.22 & \\
\hline & ZS-3 & 8.52 & & 86.34 & & 12.69 & \\
\hline \multirow{3}{*}{ FS } & FS-1 & 9.04 & \multirow{3}{*}{9.02} & 100.08 & \multirow{3}{*}{101.03} & 13.02 & \multirow{3}{*}{13.09} \\
\hline & FS-2 & 8.75 & & 92.58 & & 12.92 & \\
\hline & FS-3 & 9.26 & & 110.43 & & 13.32 & \\
\hline
\end{tabular}

Figure 4 illustrates the influence of the rock/coal strength on Young's modulus. As the pure rock strength increases, the Young's modulus tends to increase. When the coal sections of the CRC specimens were $\mathrm{M}_{1}$ and the rock section was mudstone, the average Young's modulus of these types of $\mathrm{CRC}$ specimens was $1.93 \mathrm{GPa}$. However, for the $\mathrm{M}_{1}$ and fine sandstone specimens, the average Young's modulus was 2.14 GPa. Moreover, with increasing coal strength, the average Young's modulus also tended to increase. For example, the average Young's modulus of a specimen of $\mathrm{M}_{1}$ and fine sandstone was $2.14 \mathrm{GPa}$, while that of a specimen of $\mathrm{M}_{2}$ and fine sandstone was $2.79 \mathrm{GPa}$, approximately $30.4 \%$ higher than that of the former. These phenomena indicate that the higher the uniaxial compressive strength of the pure rock/coal specimen is, the greater the stiffness is and the less likely it is to deform.

The uniaxial compressive strength average values of the CRC specimens are presented in Figure 5. The results indicate that the uniaxial compressive strength of the CRC specimens depends on the pure coal strength. For all CRC specimens, the uniaxial compressive strength increased with increasing coal section strength and appears to be independent of the rock section strength. These findings agree with the results reported by Zuo et al. [35]. During the process of quasi-static loading, the coal part 
generally exhibits relatively weak properties compared to the rock part. Thus, it can be expected that the weak properties of coal contribute significantly to the bearing capacity of the CRC specimens once loaded. In addition, the uniaxial compressive strength of these specimens is not similar, but instead is greater than that of the corresponding pure coal specimens $\mathrm{M}_{1}$ and $\mathrm{M}_{2}$. This is because when the CRC specimens were loaded, the upper rock section share part of the load so that coal section bore some another part of the load. Therefore, bearing capacity of CRC specimens is greater than that of pure coal specimens.

Figure 6 shows the statistical values of the axial strain corresponding to the peak stress (ASPS) values in different CRC specimens. First, for all CRC specimens, the ASPS was less than that of the pure rock specimen but slightly greater than that of the pure coal specimen. This result was because the stiffness of CRC specimens was located between the stiffness of the pure rock and coal specimens. Therefore, when the same load is applied, the ASPS of CRC specimens increased correspondingly. In addition, for the CRC specimens with the same coal specimen, for the $\mathrm{M}_{1}$ specimen, as the rock specimen strength increased, the ASPS varied from 9.22 to 9.43 , and the growth rate was $2.3 \%$. However, for the CRC specimens with the same rock specimen (such as mudstone), as the coal specimen strength increased, the average growth rate was $12 \%$, which was higher than the former. The findings illustrate from the other side that the strength properties of CRC specimens depend mostly on the coal strength, and the dependency of the rock strength is weak.

\subsection{Failure Mode}

Figures 7 and 8 show the typical failure modes of pure coal/rock and CRC specimens from the uniaxial compression tests. Figure 7 shows that under uniaxial compression, the rock/coal specimens failed by typical axial splitting failure, indicating that rock/coal specimens have higher brittleness. The pure coal/rock and CRC specimens have different failure modes under uniaxial compression.

Figure 8 presents photos of failed CRC specimens with different coal/rock sections. When examining the distribution of the macroscopic failure shown in Figure 8 involving CRC specimens with mudstone sections, it can be seen that the coal section failed due to typical shear failure with a single fracture surface, and the macroscopic single shear failure in the coal section extended to the rock section. Then, the rock section was broken into two parts, which failed lightly compared with the coal section. With increasing rock section strength, the coal section was broken more thoroughly, whereas the rock section was not broken. For CRC specimens with a fine sandstone section, a " $Y$ " type fracture surface was observed in the coal section, implying that this specimen exhibited a shear fracture failure mode with local axial splitting cracks. However, the failure mode of the CRC specimens with medium sandstone and siltstone exhibited a splitting fracture, which was significantly different from that obtained in the former. It can be inferred from this typical failure mode that the final destruction of the coal section is dominated by axial splitting cracks. After the CRC specimens were loaded, the coal section has the potential to expand laterally, and the relative deformation between the rock and coal section provides horizontal confinement to the coal pillar expanding laterally. With an increase in the compressive strength of the rock section, the magnitude and range of confinement stress within the coal section increased more rapidly, and as a result, lateral tensile rupture easily occurred in the coal section. Generally, in underground coal mines, the coal pillar located in the hard roof showed the progressive spalling and slabbing nature of the failure process after mining, which is in good agreement with the experimental observations. In addition, for our CRC specimens with different coal sections, with increasing coal sections, the failure mode did not change. The most obvious difference is that the coal section with higher compressive strength has greater brittleness, so the coal part was more thoroughly broken. 


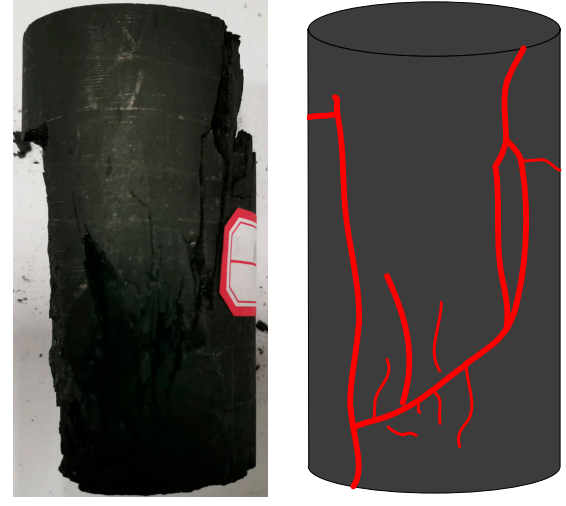

$\mathrm{M}_{1}$
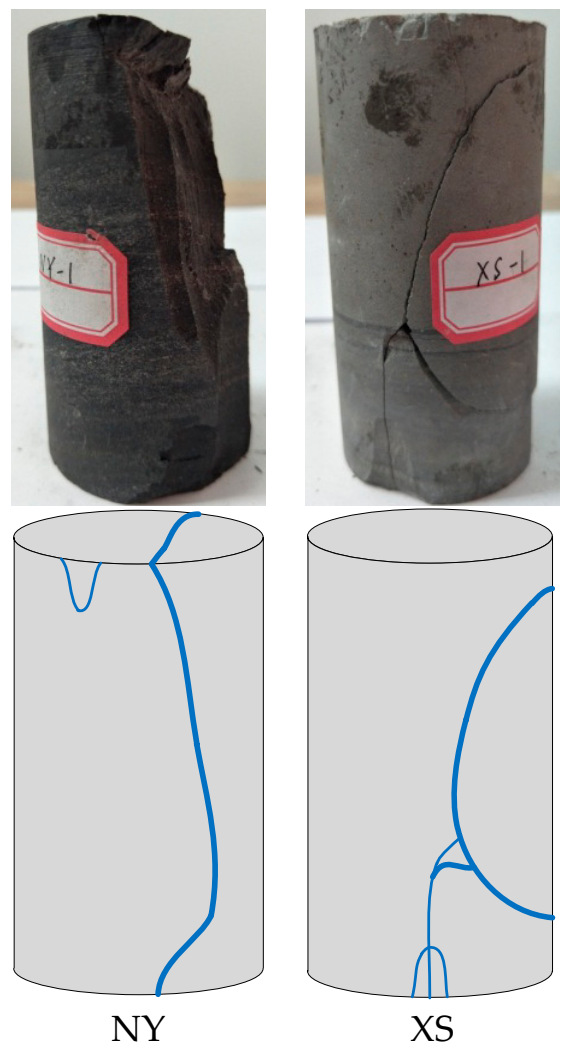

(a)

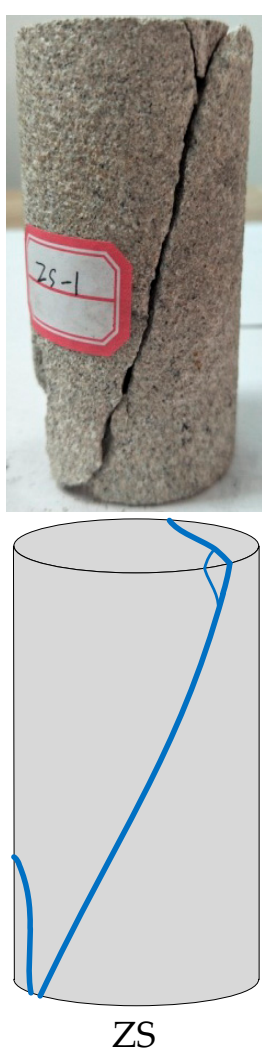

(b)
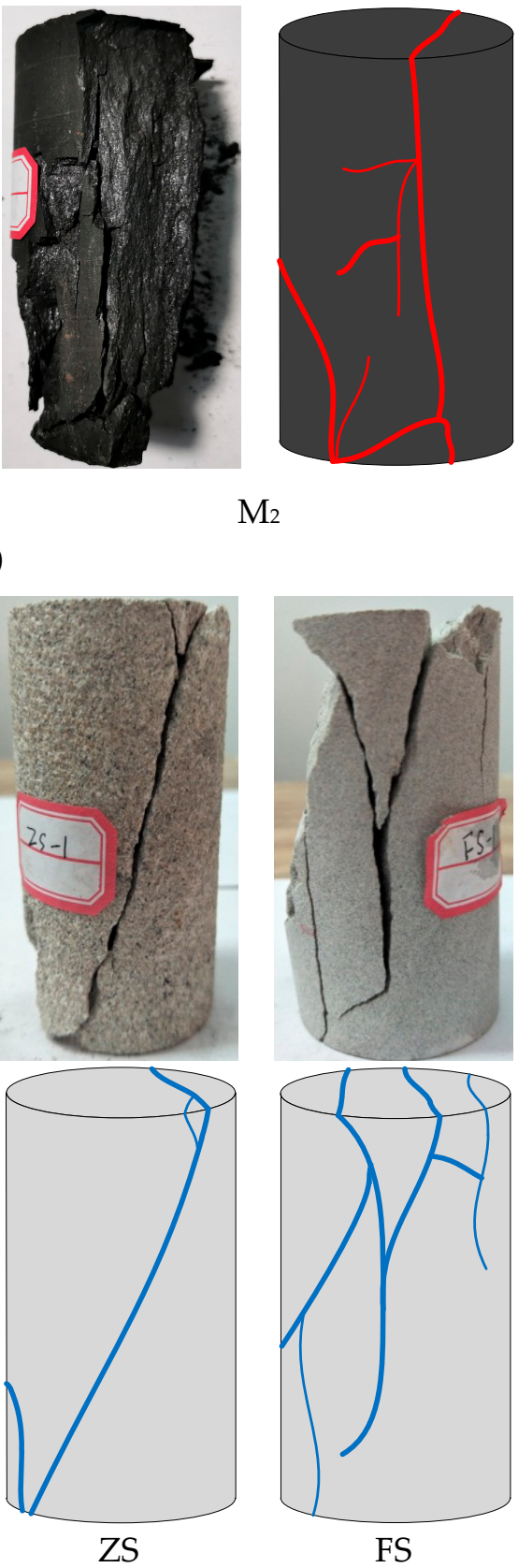

$\mathrm{M}_{2}$

FS

Figure 7. The typical failure modes of pure coal/rock: (a) The pure coal specimens; (b) The pure rock specimens. 


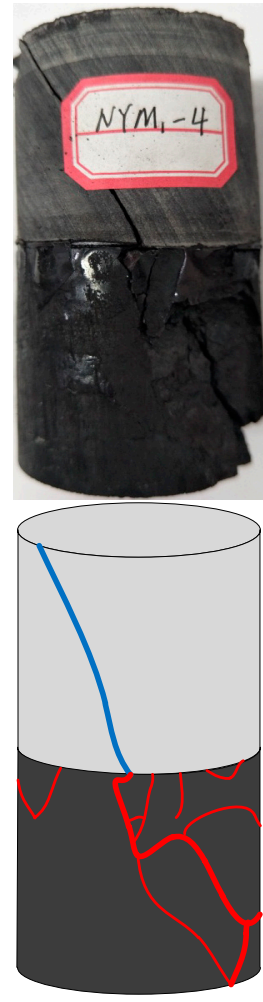

$\mathrm{NYM}_{1}$

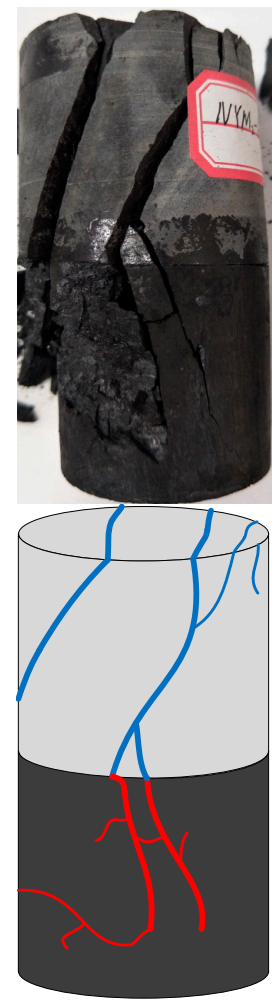

$\mathrm{NYM}_{2}$
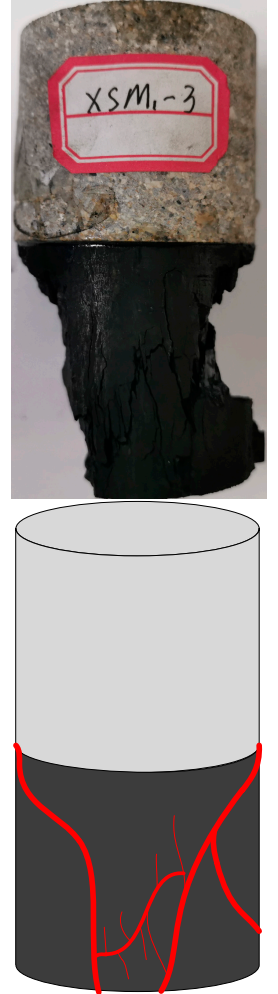

$\mathrm{XSM}_{1}$

(a)
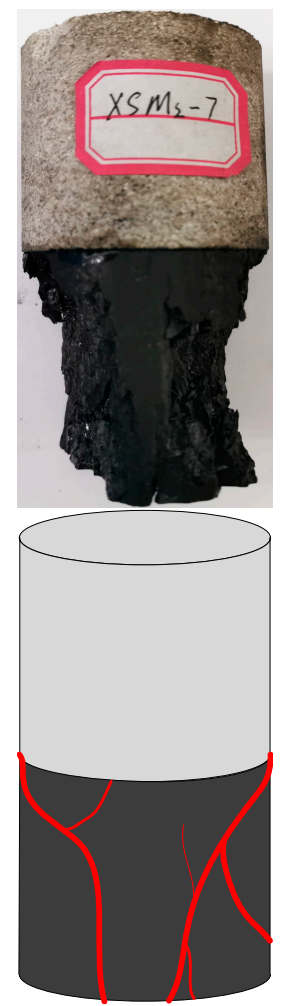

$\mathrm{XSM}_{2}$
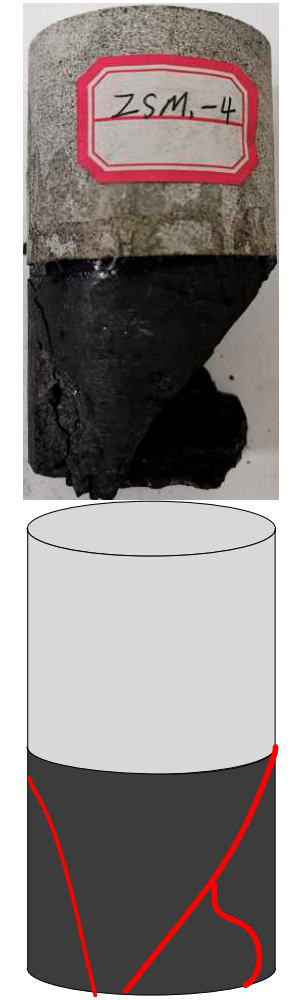

$\mathrm{ZSM}_{1}$
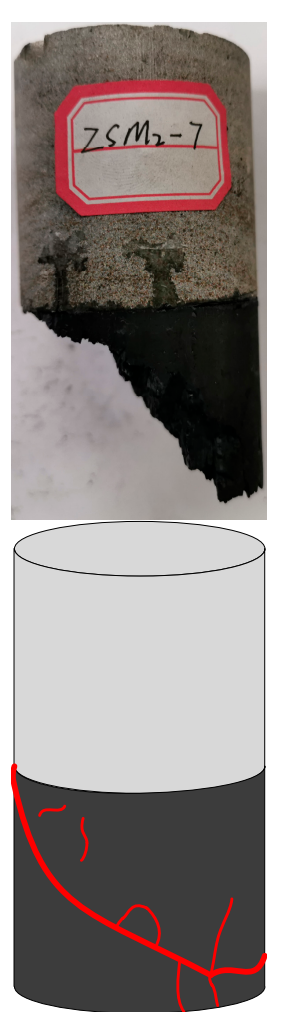

$\mathrm{ZSM}_{2}$

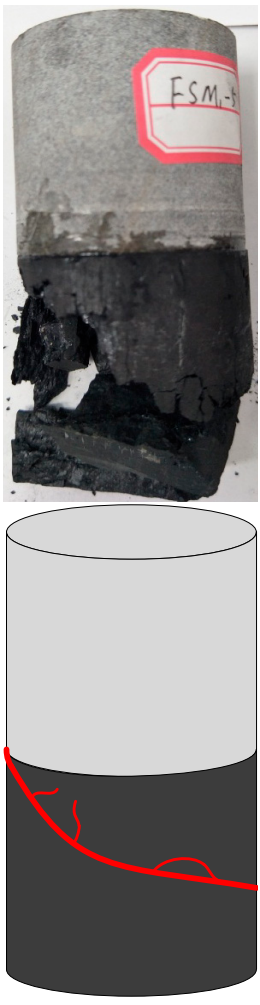

$\mathrm{FSM}_{1}$
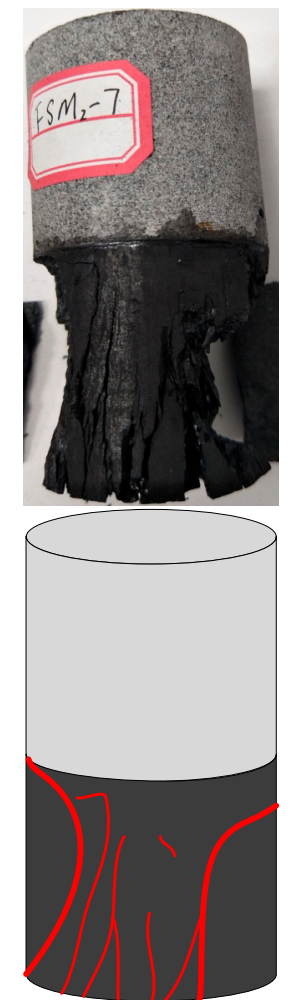

$\mathrm{FSM}_{2}$

(b)

Figure 8. the typical failure modes of the CRC specimens: (a) \#1CRC specimens; (b) \#2CRC specimens. 


\section{Energy Evolution}

\subsection{Calculation of the Released Elastic Energy $U_{e}$, Dissipated Energy $U_{d}$ and Kinetic Energy $U_{r}$ in a Unit} Coal-Rock Combined Specimen

From the perspective of energy, rock deformation and failure could be regarded as an energy-driven instability that includes energy dissipation and release. During the initial stage of loading, most of the input energy is converted into released elastic energy stored in the specimens, and a small amount is dissipated. After the specimen enters the yield stage, while a part of the input energy is dissipated by the closure, growth, and propagation of cracks, the remainder of the input energy is still stored in the form of released elastic energy. Once the released elastic energy stored in the specimens exceeds the limit value, the specimen is broken into fragments due to the release of elastic energy. During the post-peak stage, some of the released elastic energy was transformed into other forms of energy, such as surface energy and frictional energy, to promote macrofractures. Then, the remainder of the released elastic energy is converted into the kinetic energy of the ejected fragments.

At the pre-post stage, the specimen was generally regarded as a close-loop system with the assumption that there was no thermal transmission between the specimen and the external environment. Therefore, the energy balance can be described as follows:

$$
U=U_{\mathrm{e}}+U_{\mathrm{d}}
$$

where $U$ is the stored energy of a specimen unit; $U_{\mathrm{e}}$ represents the released elastic energy in the specimen; $U_{\mathrm{d}}$ represents the dissipated energy owing to inelastic deformation and the closure, growth, and propagation of cracks.

Based on the stress-strain curve of the specimen under uniaxial cyclic loading and unloading compression, we can determine the stored energy $U$, released elastic energy $U_{\mathrm{e}}$ and dissipated energy $U_{\mathrm{d}}$ at each cyclic loading and unloading compression, as shown in Figure 9. The stored energy $U$ $(\mathrm{OAB})$ of the specimen is represented by the area under the loading stress-strain curve. The released elastic energy $U_{e}(A B C D)$ at point $A$ is represented by the area under the unloading stress-strain curve. The area between the loading and unloading stress-strain curves represents the dissipated energy $U_{\mathrm{d}}$ (OADC). According to the method suggested by Meng et al. [36] and Peng et al. [26], the stored energy $U$ and released elastic energy $U_{\mathrm{e}}$ can be determined by the integral of the corresponding stress-strain curves. Based on the definition of integral calculus, the equations for the related energies are as follows:

$$
\begin{gathered}
U_{\mathrm{d}}=U-U_{\mathrm{e}} \\
U=\int_{0}^{\varepsilon_{2}} \sigma_{i} d \varepsilon_{i} \\
U_{e}=\int_{\varepsilon_{1}}^{\varepsilon_{2}} \sigma_{i} d \varepsilon_{i} \\
U_{\mathrm{d}}=\int_{0}^{\varepsilon_{2}} \sigma_{i} d \varepsilon_{i}-\int_{\varepsilon_{1}}^{\varepsilon_{2}} \sigma_{i} d \varepsilon_{i}
\end{gathered}
$$

where $\varepsilon_{1}$ is the strain value, which corresponds to the stress loading to the $\sigma_{1}$ unloading point, and $\varepsilon_{2}$ is the strain value, which corresponds to the stress unloading to $\sigma_{2}$. 


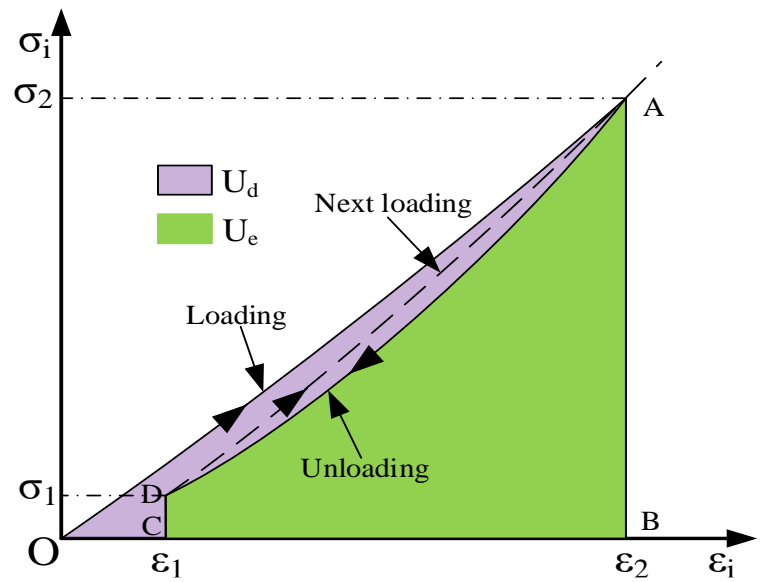

Figure 9. Relationship between the dissipated energy and elastic release energy of CRC specimens during cyclic loading and unloading.

Zhang et al. [37] suggested that rock materials with higher brittleness display self-sustaining fracturing during the post-peak stage. In other words, no additional energy is required for rock failure at the post-peak stage, and the elastic energy at peak point $\sigma_{c}\left(U_{e c}\right)$ is sufficient to sustain macroscopic fracturing. At the post-peak stage, some of $U_{e c}$ was dissipated owing to failure occurrence, and the remainder will be converted into kinetic energy $U_{r}$. If the kinetic energy is large enough, then the brittle rock material fragments will be ejected at a high speed. In this section, the energy that consumed in the post-peak stage was called post-peak failure energy $U_{e d}$. According to the method suggested by Zhang et al. [37], the zone under the post-peak stress-strain curve represented post-peak failure energy $\left(U_{e d}\right)$, as shown in Figure 10, was determined by the integral of the corresponding post-peak stress-strain curve and it can be calculated as:

$$
U_{e d}=\int_{\varepsilon_{c}}^{\varepsilon_{3}} \sigma_{i} d \varepsilon_{i}
$$

where $\varepsilon_{\mathcal{c}}$ is the strain value corresponding to the stress loading to the $\sigma_{\mathcal{c}}$ unloading point, and $\varepsilon_{3}$ is the strain value corresponding to the stress unloading to $\sigma_{3}$.

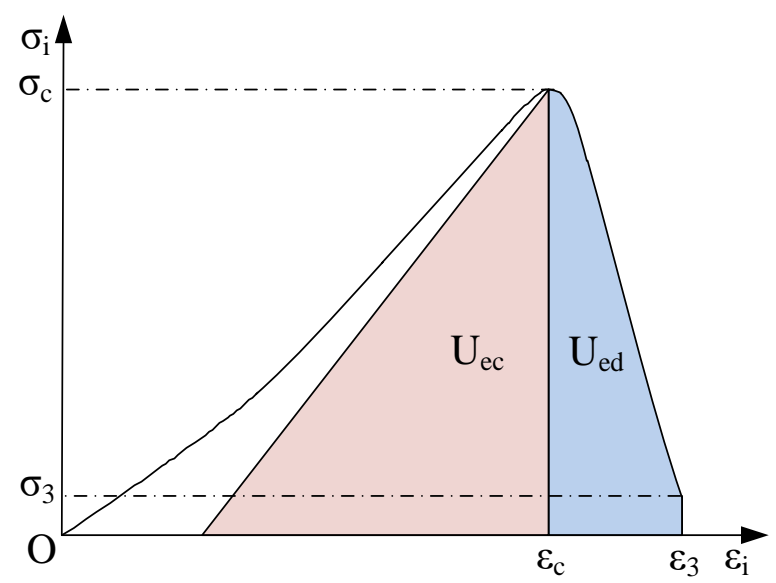

Figure 10. Relationship between the kinetic energy and the elastic release energy, and the post-peak failure energy of CRC specimens during cyclic loading and unloading.

According to the first law of thermodynamics, the equations for the kinetic energy was expressed as:

$$
U_{r}=U_{e c}-U_{e d}
$$


where $U_{e c}$ is the elastic release energy at peak point $\sigma_{c}$. It is noted that the specimen was difficult to unload at peak stress. Based on this, uniaxial cyclic loading and unloading compression tests were carried out, and the testing programs are described in Section 2. These tests were conducted to obtain the relationship between the released elastic energy and the stress state. If a given stress state, such as the peak stress, was known, then the corresponding released elastic energy could be accurately estimated.

\subsection{Dissipated Energy and Released Elastic Energy at Peak Stress}

Uniaxial cyclic loading and unloading compression tests have been carried out to obtain the dissipated energy $U_{\mathrm{d}}$ and the released elastic energy $U_{\mathrm{e}}$ at peak stress. Figure 11 shows the complete stress-strain curve of the CRC specimens under uniaxial cyclic loading and unloading compression, and the results agree well with the experimental results by Yang et al. [38]. We focused mainly on the variation in the dissipated energy $U_{\mathrm{d}}$ and the released elastic energy $U_{\mathrm{e}}$.

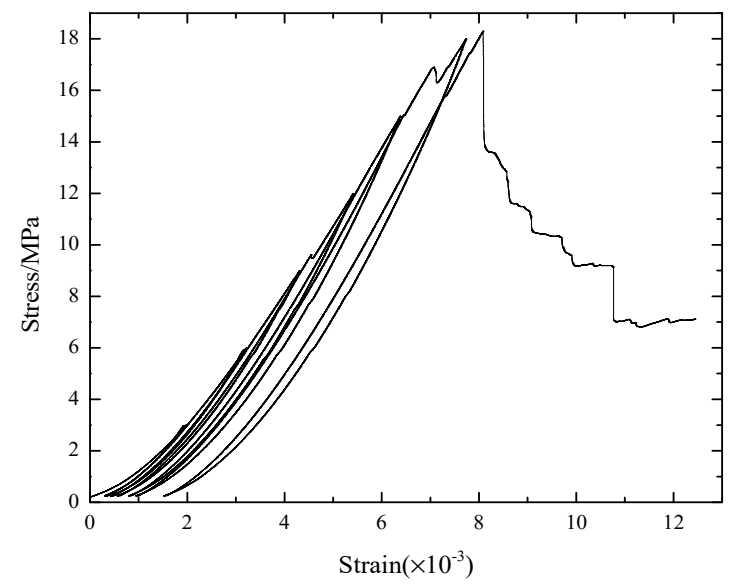

(a)

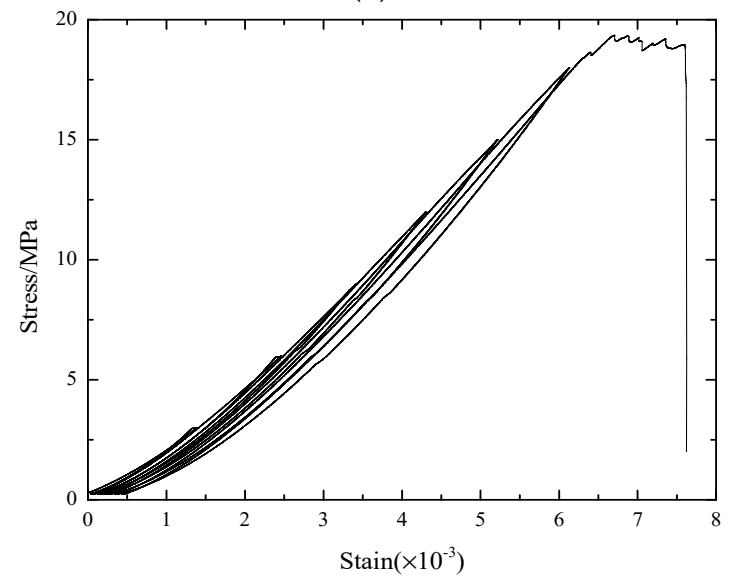

(c)

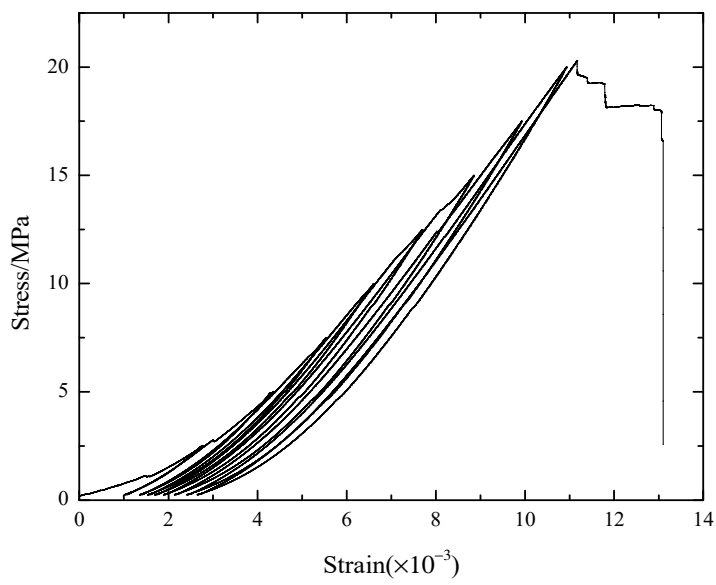

(b)

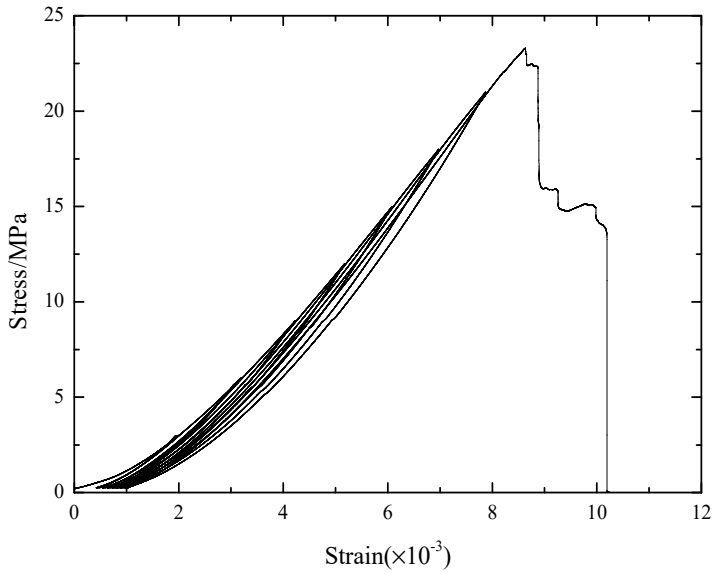

(d)

Figure 11. Cont. 


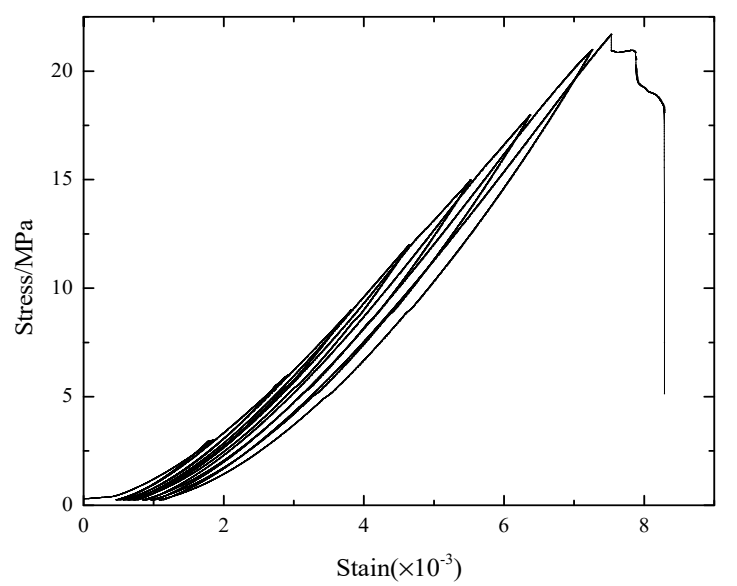

(e)

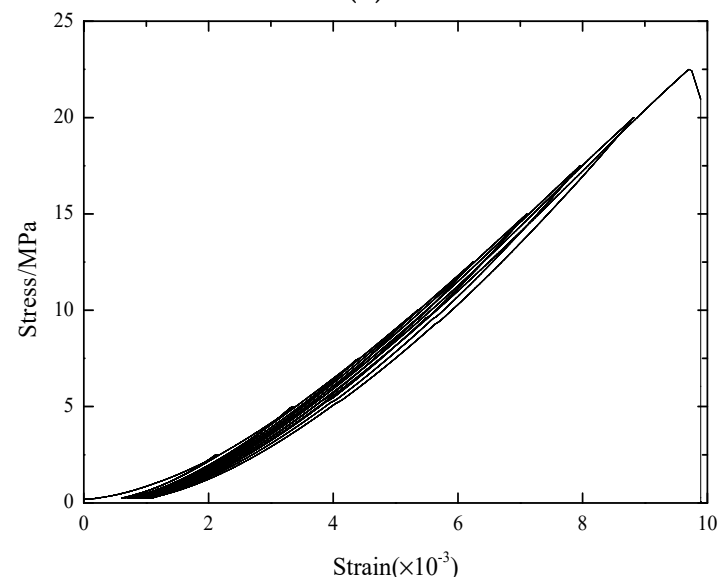

(g)

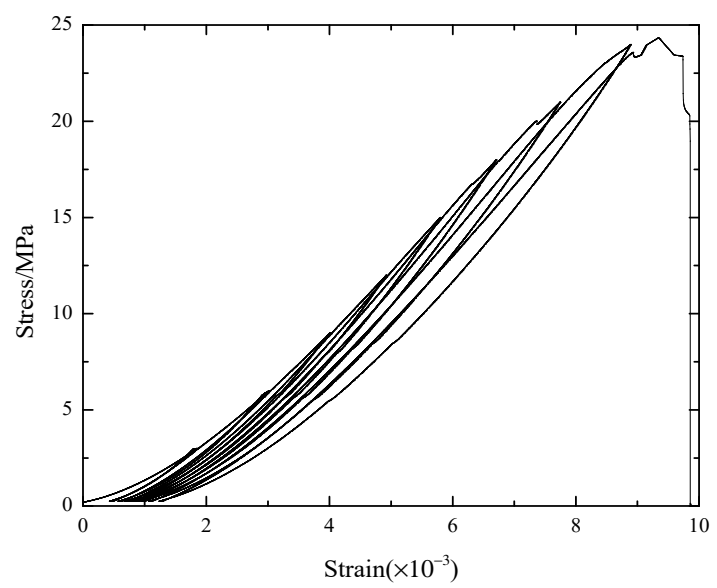

(f)

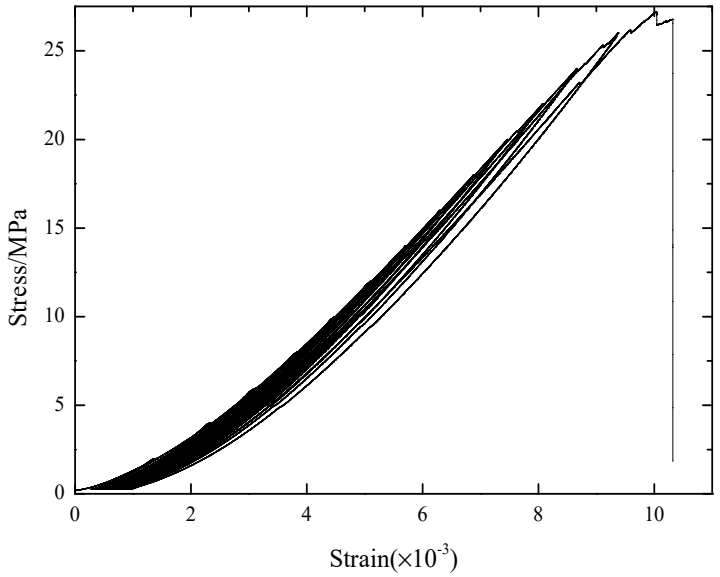

(h)

Figure 11. The complete stress-strain curve of the CRC specimens under uniaxial cyclic loading and unloading compression: (a) $\mathrm{NYM}_{1}-3$; (b) $\mathrm{NYM}_{2}-6$; (c) $\mathrm{XSM}_{1}-5$; (d) $\mathrm{XSM}_{2}-6$; (e) $\mathrm{ZSM}_{1}-4$; (f) $\mathrm{ZSM}_{2}-6$; (g) $\mathrm{FSM}_{1}-3$; (h) $\mathrm{FSM}_{2}-7$.

First, using the methods described in Section 4.1, the released elastic energy $U_{\mathrm{e}}$ and dissipated energy $U_{\mathrm{d}}$ were calculated at each cyclic loading and unloading compression. Then, to model the growth of $U_{\mathrm{e}}$ and $U_{\mathrm{d}}$ with the stressed state, the $U_{\mathrm{e}}$ and $U_{\mathrm{d}}$ of the CRC specimens were fitted accurately using an power function, the typical fitting curve of $U_{\mathrm{e}}$ and $U_{\mathrm{d}}$ are shown in Figure 12 and the model parameters are listed in Table 3. The correlation coefficients range from 0.9658 to 0.9999 , indicating that the proposed formula produces accurate results. Third, the proposed formula was used to accurately estimate $U_{\mathrm{e}}$ and $U_{\mathrm{d}}$ when the peak strength is known. Table 3 . shows the variation in the released elastic energy $U_{\mathrm{e}}$ and dissipated energy $U_{\mathrm{d}}$ with the rock/coal strength.

As shown in Table 3 , the released elastic energy $U_{\mathrm{e}}$ monotonically increases with increasing rock strength. Generally, with increasing rock section strength, the CRC specimen strength increased. From the perspective of energy, rock material with higher strength has a greater ability to store energy. Therefore, the $U_{\mathrm{e}}$ of the CRC specimens with higher strength was the largest. It can be deduced that more strain energy could be stored in the coal pillar located in the hard roof, and some active prevention techniques should be used to weaken the energy accumulation. In addition, the higher the coal section strength is, the greater the $U_{\mathrm{e}}$ of the CRC specimens is. This result may indicate that the coal section strength has a great influence on the accumulation of $U_{\mathrm{e}}$. 


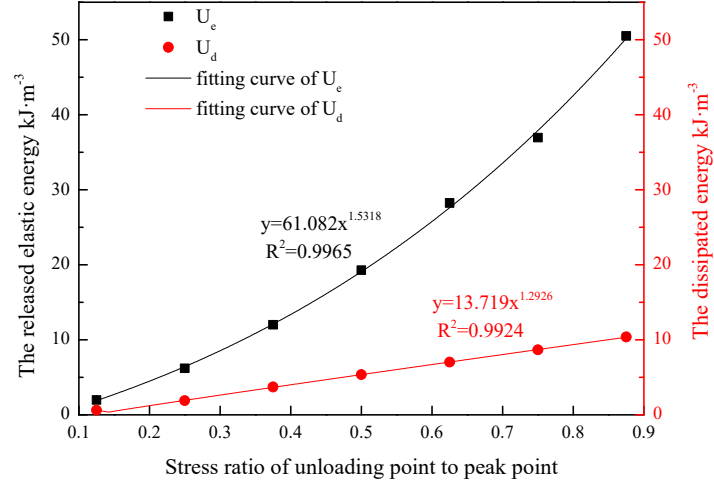

(a)

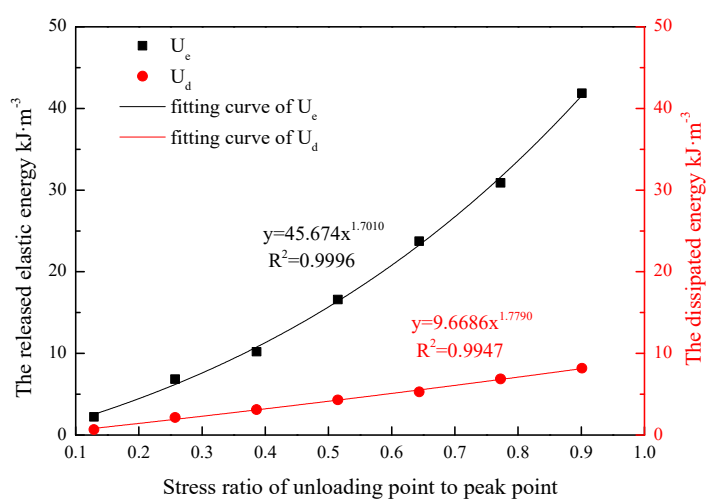

(b)

Figure 12. The typical fitting curves of $U_{\mathrm{e}}$ and $U_{\mathrm{d}}$ : (a) $\mathrm{ZSM}_{1}-4$; (b) $\mathrm{XSM}_{2}-6$.

Table 3. Fitted values of the constants $a, b$.

\begin{tabular}{|c|c|c|c|c|c|c|c|}
\hline & \multirow{2}{*}{$\begin{array}{l}\text { Specimen } \\
\text { Label }\end{array}$} & \multicolumn{3}{|c|}{$U_{e}\left(y=a x^{b}\right)$} & \multicolumn{3}{|c|}{$U_{\mathrm{d}}\left(\mathrm{y}=a x^{b}\right)$} \\
\hline & & a & b & $\mathbf{R}^{2}$ & a & b & $\mathbf{R}^{2}$ \\
\hline \multirow{3}{*}{$\mathrm{NYM}_{1}$} & $\mathrm{NYM}_{1}-3$ & 21.540 & 1.7489 & 0.9830 & 4.8265 & 1.2123 & 0.9936 \\
\hline & $\mathrm{NYM}_{1}-4$ & 14.753 & 1.7808 & 0.9999 & 3.2803 & 1.4403 & 0.9746 \\
\hline & $\mathrm{NYM}_{1}-5$ & 40.294 & 1.2797 & 0.9975 & 8.9718 & 1.1034 & 0.9658 \\
\hline \multirow{3}{*}{$\mathrm{NYM}_{2}$} & $\mathrm{NYM}_{2}-6$ & 32.291 & 1.6328 & 0.9979 & 7.1048 & 1.7519 & 0.9684 \\
\hline & $\mathrm{NYM}_{2}-7$ & 32.975 & 1.6332 & 0.9998 & 7.2514 & 1.5806 & 0.9883 \\
\hline & $\mathrm{NYM}_{2}-8$ & 35.861 & 1.6122 & 0.9985 & 7.9021 & 1.6552 & 0.9921 \\
\hline \multirow{3}{*}{$\mathrm{XSM}_{1}$} & $\mathrm{XSM}_{1}-3$ & 50.066 & 1.6504 & 0.9972 & 11.020 & 1.2012 & 0.9951 \\
\hline & $\mathrm{XSM}_{1}-4$ & 58.152 & 1.5869 & 0.9991 & 12.864 & 1.6816 & 0.99 \\
\hline & $\mathrm{XSM}_{1}-5$ & 47.253 & 1.6992 & 0.9986 & 9.9792 & 1.0972 & 0.9965 \\
\hline \multirow{3}{*}{$\mathrm{XSM}_{2}$} & $\mathrm{XSM}_{2}-6$ & 45.674 & 1.7010 & 0.9996 & 9.6686 & 1.7790 & 0.9947 \\
\hline & $\mathrm{XSM}_{2}-7$ & 62.513 & 1.6668 & 0.9997 & 13.849 & 1.5155 & 0.9931 \\
\hline & $\mathrm{XSM}_{2}-8$ & 56.652 & 1.6584 & 0.9958 & 12.4921 & 1.5854 & 0.9915 \\
\hline \multirow{3}{*}{$\mathrm{ZSM}_{1}$} & $\mathrm{ZSM}_{1}-3$ & 58.566 & 1.6986 & 0.9995 & 12.842 & 1.6639 & 0.9977 \\
\hline & $\mathrm{ZSM}_{1}-4$ & 61.082 & 1.5318 & 0.9965 & 13.719 & 1.2926 & 0.9924 \\
\hline & $\mathrm{ZSM}_{1}-5$ & 62.409 & 1.6031 & 0.9998 & 14.434 & 1.3630 & 0.9968 \\
\hline \multirow{3}{*}{$\mathrm{ZSM}_{2}$} & $\mathrm{ZSM}_{2}-6$ & 54.130 & 1.7213 & 0.9994 & 12.101 & 1.6692 & 0.9904 \\
\hline & $\mathrm{ZSM}_{2}-7$ & 79.558 & 1.6149 & 0.9986 & 17.521 & 1.2570 & 0.9895 \\
\hline & $\mathrm{ZSM}_{2}-8$ & 70.452 & 1.6583 & 0.9958 & 15.523 & 1.5825 & 0.9916 \\
\hline \multirow{3}{*}{$\mathrm{FSM}_{1}$} & $\mathrm{FSM}_{1}-3$ & 58.169 & 1.6589 & 0.9994 & 12.856 & 1.2897 & 0.9984 \\
\hline & $\mathrm{FSM}_{1}-4$ & 88.075 & 1.5815 & 0.9875 & 19.093 & 1.5520 & 0.9964 \\
\hline & $\mathrm{FSM}_{1-5}$ & 82.735 & 1.7108 & 0.9900 & 18.311 & 1.8993 & 0.9908 \\
\hline \multirow{3}{*}{$\mathrm{FSM}_{2}$} & $\mathrm{FSM}_{2}-6$ & 77.877 & 1.9218 & 0.9544 & 17.310 & 1.8039 & 0.9949 \\
\hline & $\mathrm{FSM}_{2}-7$ & 88.877 & 1.6844 & 0.9996 & 19.529 & 1.7700 & 0.9835 \\
\hline & $\mathrm{FSM}_{2}-8$ & 80.256 & 1.6524 & 0.9788 & 17.721 & 1.7965 & 0.9937 \\
\hline
\end{tabular}

It should be noted that the dissipated energy $U_{\mathrm{d}}$ also increased with rock/coal section strength. This increase indicates that the damage degree of the CRC specimen corresponding to the peak stress values increases with increasing rock/coal section strength. This finding is because a sufficiently developed crack gradually appears in the CRC specimen with higher rock/coal section strength, and more energy was consumed due to crack propagation. 


\subsection{Kinetic Energy at the Failure Stage}

The important feature of the violent fracture of the rock material was the release of energy. It has been proposed by Anikolenkoi et al. [39] that the kinetic energy could represent the energy released at the time of rock fracture.

As shown in Table 4, as the rock/coal strength increases, the kinetic energy of the CRC specimen also increased. This result indicated that a higher strength CRC specimen contributes more to the problem of energy release and then leads to violent fracture because these specimens will accumulate large amounts of elastic strain energy prior to failure. This is the most fundamental reason why the violent fractures of coal pillars with hard roofs are much greater than those located in weak roofs.

Table 4. The kinetic energy of the CRC specimens.

\begin{tabular}{|c|c|c|c|c|c|c|c|}
\hline & $\begin{array}{l}\text { Specimen } \\
\text { Label }\end{array}$ & $\begin{array}{c}U_{e c} \\
\left(\mathbf{k J} \cdot \mathbf{m}^{-3}\right)\end{array}$ & Average & $\underset{\left(\mathrm{kJ} \cdot \mathrm{m}^{-3}\right)}{U_{e d}}$ & Average & $\begin{array}{c}U_{r} \\
\left(\mathbf{k J} \cdot \mathbf{m}^{-3}\right)\end{array}$ & Average \\
\hline \multirow{3}{*}{$\mathrm{NYM}_{1}$} & $\mathrm{NYM}_{1}-3$ & 21.54 & \multirow{3}{*}{25.53} & 11.25 & \multirow{3}{*}{13.24} & 10.29 & \multirow{3}{*}{12.29} \\
\hline & $\mathrm{NYM}_{1}-4$ & 14.75 & & 8.82 & & 5.93 & \\
\hline & $\mathrm{NYM}_{1}-5$ & 40.29 & & 19.65 & & 20.64 & \\
\hline \multirow{3}{*}{$\mathrm{NYM}_{2}$} & $\mathrm{NYM}_{2}-6$ & 32.29 & \multirow{3}{*}{33.71} & 11.25 & \multirow{3}{*}{11.14} & 21.04 & \multirow{3}{*}{22.57} \\
\hline & $\mathrm{NYM}_{2}-7$ & 32.98 & & 12.05 & & 20.93 & \\
\hline & $\mathrm{NYM}_{2}-8$ & 35.86 & & 10.12 & & 25.74 & \\
\hline \multirow{3}{*}{$\mathrm{XSM}_{1}$} & $\mathrm{XSM}_{1}-3$ & 50.07 & \multirow{3}{*}{51.82} & 8.25 & \multirow{3}{*}{8.44} & 41.82 & \multirow{3}{*}{43.38} \\
\hline & $\mathrm{XSM}_{1}-4$ & 58.15 & & 9.62 & & 48.53 & \\
\hline & $\mathrm{XSM}_{1}-5$ & 47.25 & & 7.45 & & 39.80 & \\
\hline \multirow{3}{*}{$\mathrm{XSM}_{2}$} & $\mathrm{XSM}_{2}-6$ & 45.67 & \multirow{3}{*}{54.95} & 7.52 & \multirow{3}{*}{7.80} & 38.15 & \multirow{3}{*}{47.15} \\
\hline & $\mathrm{XSM}_{2}-7$ & 62.51 & & 7.86 & & 54.65 & \\
\hline & $\mathrm{XSM}_{2}-8$ & 56.65 & & 8.02 & & 48.63 & \\
\hline \multirow{3}{*}{$\mathrm{ZSM}_{1}$} & $\mathrm{ZSM}_{1}-3$ & 58.57 & \multirow{3}{*}{60.69} & 6.32 & \multirow{3}{*}{6.62} & 52.25 & \multirow{3}{*}{54.07} \\
\hline & $\mathrm{ZSM}_{1}-4$ & 61.08 & & 6.55 & & 54.53 & \\
\hline & $\mathrm{ZSM}_{1}-5$ & 62.41 & & 6.98 & & 55.43 & \\
\hline \multirow{3}{*}{$\mathrm{ZSM}_{2}$} & $\mathrm{ZSM}_{2}-6$ & 54.13 & \multirow{3}{*}{68.05} & 6.05 & \multirow{3}{*}{5.52} & 48.08 & \multirow{3}{*}{62.52} \\
\hline & $\mathrm{ZSM}_{2}-7$ & 79.56 & & 5.02 & & 74.54 & \\
\hline & $\mathrm{ZSM}_{2}-8$ & 70.45 & & 5.5 & & 64.95 & \\
\hline \multirow{3}{*}{$\mathrm{FSM}_{1}$} & $\mathrm{FSM}_{1}-3$ & 58.17 & \multirow{3}{*}{76.33} & 3.25 & \multirow{3}{*}{3.28} & 54.92 & \multirow{3}{*}{73.05} \\
\hline & $\mathrm{FSM}_{1}-4$ & 88.08 & & 3.55 & & 84.53 & \\
\hline & $\mathrm{FSM}_{1}-5$ & 82.74 & & 3.03 & & 79.71 & \\
\hline \multirow{3}{*}{$\mathrm{FSM}_{2}$} & $\mathrm{FSM}_{2}-6$ & 77.88 & \multirow{3}{*}{82.34} & 3.11 & \multirow{3}{*}{2.57} & 74.78 & \multirow{3}{*}{79.77} \\
\hline & $\mathrm{FSM}_{2}-7$ & 88.88 & & 2.12 & & 86.78 & \\
\hline & $\mathrm{FSM}_{2}-8$ & 80.26 & & 2.51 & & 77.76 & \\
\hline
\end{tabular}

To further reveal the dependence of the kinetic energy on the rock/coal strength, the variation in the kinetic energy with the rock/coal strength is shown in Figure 13. The X-axis is the ratio of the rock strength to coal strength. In Figure 13, it can be observed that for the CRC specimens with the same coal section, the greater the difference in strength between the rock and coal is, the larger the kinetic energy is. Generally, the rock section with a higher strength has a greater ability to store elastic energy. When the CRC specimens with a higher strength rock section were loaded, the rock section accumulated more elastic energy than the coal section stored. Once the CRC specimens fail due to loading, some elastic energy stored in the rock section is released into the coal section, and the coal section is broken. Therefore, energy release was due to the difference in strength between the rock and coal. 


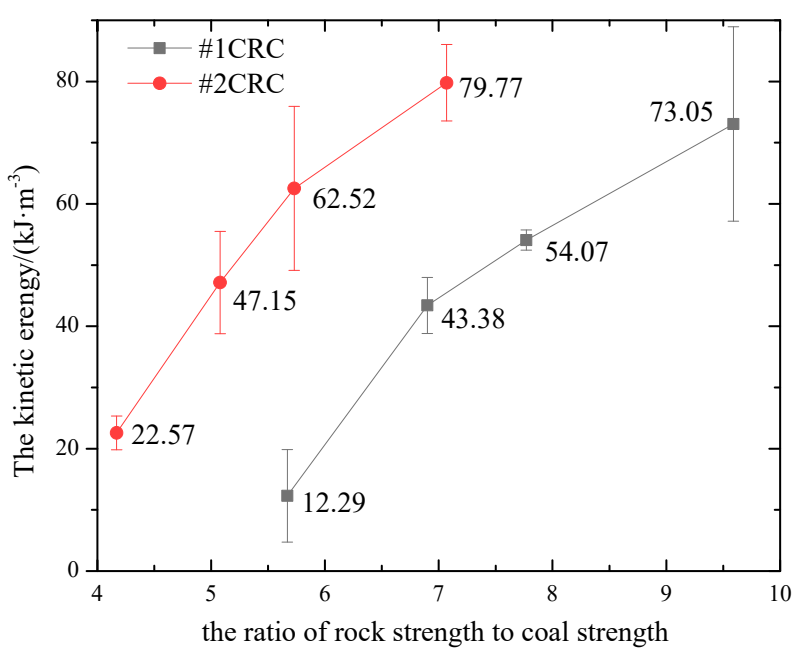

Figure 13. Relationship between the kinetic energy and rock/coal strength in CRC specimens.

\section{Conclusions}

In this paper, the effect of the rock/coal strength on uniaxial compressive strength, failure behavior, and energy evolution of CRC specimens were studied by uniaxial compression, uniaxial cyclic loading, and unloading experiments. The following conclusions were obtained:

(1) The stress-strain curve of the uniaxial compression test of the CRC specimen is located between the pure coal specimen and the pure rock specimen, and the strength of the CRC specimen is greater than the strength of the pure coal specimen, which is smaller than that of the pure rock specimen. The Young's modulus, uniaxial compressive strength, and axial strain of the CRC specimen tend to increase with an increase in the coal strength instead of the rock strength.

(2) The pure coal and pure rock specimens exhibited typical axial splitting failure. For the CRC specimen under uniaxial compression, when the strength of the rock is small, the shear failure in the coal section extends to the rock section. When the strength of the rock specimen is large, the coal section exhibits partial splitting damage, and the rock section does not substantially break. This finding also indicates that the stability of the CRC specimen depends mainly on the strength of the coal.

(3) According to the failure mode of CRC specimens, the final destruction of CRC specimens with coal section was dominated by axial splitting. In addition, lateral tensile ruptured easily in the coal section, as such, it is suggested that lateral support of coal pillar should be strengthened in the mining field.

(4) The elastic release energy $U_{\mathrm{e}}$, the dissipative energy $U_{\mathrm{d}}$, and the kinetic energy $U_{r}$ increase with an increase in the rock/coal strength. Additionally, for the CRC specimen with the same coal section, as the strength of the rock increases, the more severe the damage of the CRC specimen is, the greater the kinetic energy is. In addition, more strain energy could be stored in the coal pillar located in the hard roof. As such, it is suggested that some active prevention techniques should be used to weaken the energy accumulation.

Author Contributions: All authors have contributed to this work. S.Y. and J.W. conceived the experimental plan and wrote the paper, J.N. revised the paper, P.Q. conducted the data analysis.

Funding: The research described in this paper was financially supported by National Key R\&D Program of China (No. 2018YFC0604703); National Natural Science Foundation of China (No. 5157414); Natural Science Foundation of Shandong Province, China (No. ZR2019QEE002); Key R\&D Programs of Shandong Province (No. 2018GSF116003); SDUST Graduate Student Technology Innovation Project (No. SDKDYC190116).

Conflicts of Interest: The authors declare no conflict of interest. 


\section{References}

1. Ghasemi, E.; Shahriar, K. A new coal pillars design method in order to enhance safety of the retreat mining in room and pillar mines. Saf. Sci. 2012, 50, 579-585. [CrossRef]

2. Mandal, P.K.; Singh, R.; Maiti, J.; Singh, A.K.; Kumar, R.; Sinha, A. Underpinning-based simultaneous extraction of contiguous sections of a thick coal seam under weak and laminated parting. Int. J. Rock Mech. Min. Sci. 2008, 45, 11-28. [CrossRef]

3. Vardar, O.; Tahmasebinia, F.; Zhang, C.; Canbulat, I.; Saydam, S. A review of uncontrolled pillar failures. Proc. Eng. 2017, 191, 631-637. [CrossRef]

4. Horst, W. Deep Mining: A Rock Engineering Challenge. Rock Mech. Rock Eng. 2019, 52, 1417-1446.

5. Zipf, R.; Mark, C. Design methods to control violent pillar failures in room-and-pillar mines. Trans. Inst. Min. Metall.-Sect. A-Min. Ind. 1997, 106, A124-A132.

6. Ghasemi, E.; Ataei, M.; Shahriar, K.; Sereshki, F.; Jalali, S.E.; Ramazanzadeh, A. Assessment of roof fall risk during retreat mining in room and pillar coal mines. Int. J. Rock Mech. Min. Sci. 2012, 54, 80-89. [CrossRef]

7. Murphy, M. Shale Failure Mechanics and Intervention Measures in Underground Coal Mines: Results from 50 Years of Ground Control Safety Research. Rock Mech. Rock Eng. 2016, 49, 661-671. [CrossRef]

8. Wang, J.; Ning, J.; Jiang, L.; Jiang, J.Q.; Bu, T. Structural characteristics of strata overlying of a fully mechanized longwall face: A case study. J. S. Afr. Inst. Min. Metall. 2018, 118, 1195-1204. [CrossRef]

9. Stacey, T. Addressing the Consequences of Dynamic Rock Failure in Underground Excavations. Rock Mech. Rock Eng. 2016, 49, 4091-4101. [CrossRef]

10. Wang, J.; Ning, J.; Qiu, P.; Yang, S.; Shang, H. Microseismic monitoring and its precursory parameter of hard roof collapse in longwall faces: A case study. Geomech. Eng. 2019, 17, 375-383.

11. Kong, P.; Jiang, L.; Shu, J.; Sainoki, A.; Wang, Q. Effect of fracture heterogeneity on rock mass stability in a highly heterogeneous underground roadway. Rock Mech. Rock Eng. 2019, 1-18. [CrossRef]

12. Butenuth, C. Comparison of Tensile Strength Values of Rocks Determined by Point Load and Direct Tension Tests. Rock Mech. Rock Eng. 1997, 30, 65-72. [CrossRef]

13. Cai, M. Practical Estimates of Tensile Strength and Hoek-Brown Strength Parameter mi of Brittle Rocks. Rock Mech. Rock Eng. 2010, 43, 167-184. [CrossRef]

14. Buzzi, O.; Sieffert, Y.; Mendes, J.; Liu, X.; Giacomini, A.; Seedsman, R. Strength of an Australian Coal under Low Confinement. Rock Mech. Rock Eng. 2014, 47, 2265-2270. [CrossRef]

15. Guo, W.; Gu, Q.; Tan, Y.; Hu, S. Case studies of rock bursts in tectonic areas with facies change. Energies 2019, 12, 1330. [CrossRef]

16. Taehyun, K.; Seokwon, J. Experimental Study on Shear Behavior of a Rock Discontinuity under Various Thermal, Hydraulic and Mechanical Conditions. Rock Mech. Rock Eng. 2019, 52, 2207-2226.

17. Das, A.J.; Mandal, P.K.; Paul, P.S.; Sinha, R.K.; Tewari, S. Assessment of the Strength of Inclined Coal Pillars through Numerical Modelling Based on the Ubiquitous Joint Model. Rock Mech. Rock Eng. 2018, 1-27. [CrossRef]

18. Guo, W.Y.; Tan, Y.L.; Yu, F.H.; Zhao, T.B.; Hu, S.C.; Huang, D.M.; Qin, Z. Mechanical behavior of rock-coal-rock specimens with different coal thicknesses. Geomech. Eng. 2018, 15, 1017-1027.

19. Wang, N.; Xu, Y.; Zhu, D.; Wang, N.; Yu, B. Acoustic Emission and Failure Modes for Coal-Rock Structure under Different Loading Rates. Adv. Civ. Eng. 2018, 2018, 9391780. [CrossRef]

20. Zhao, T.B.; Guo, W.Y.; Lu, C.P.; Zhao, G.M. Failure characteristics of combined coal-rock with different interfacial angles. Geomech. Eng. 2016, 3, 345-359. [CrossRef]

21. Huang, B.X.; Liu, J.W. The effect of loading rate on the behavior of samples composed of coal and rock. Int. J. Rock Mech. Min. Sci. 2013, 61, 23-30. [CrossRef]

22. Bai, J.; Feng, G.; Wang, Z.; Wang, S.; Qi, T.; Wang, P. Experimental investigations on the progressive failure characteristics of a sandwiched coal-rock system under uniaxial compression. Appl. Sci. 2019, 9, 1195. [CrossRef]

23. Chen, S.J.; Yin, D.W.; Jiang, N.; Wang, F.; Zhao, Z.H. Mechanical properties of oil shale-coal composite samples. Int. J. Rock. Mech. Min. Sci. 2019, 123, 104120. [CrossRef]

24. Cook, N.G.; Hoek, E.; Pretorius, J.P.; Ortlepp, W.D.; Salamon, M.D. Rock mechanics applied to the study of rockburst. J. S. Afr. I. Min. Metall. 1966, 66, 435-528. 
25. Xie, H.; Li, L.; Ju, Y.; Peng, R.; Yang, Y. Energy analysis for damage and catastrophic failure of rocks. Sci. China Technol. Sci. 2011, 54, 199-209. [CrossRef]

26. Peng, R.; Ju, Y.; Wang, J.G.; Xie, H.; Gao, F.; Mao, L. Energy Dissipation and Release during Coal Failure Under Conventional Triaxial Compression. Rock Mech. Rock Eng. 2015, 48, 509-526. [CrossRef]

27. Bagde, M.; Petros, V. Fatigue properties of intact sandstone samples subjected to dynamic uniaxial cyclical loading. Int. J. Rock Mech. Min. Sci. 2005, 42, 237-250. [CrossRef]

28. Wasantha, P.; Ranjith, P.; Shao, S. Energy monitoring and analysis during deformation of bedded-sandstone: Use of acoustic emission. Ulrasonics 2014, 54, 217-226. [CrossRef]

29. Liu, Y.; Lu, C.P.; Zhang, H.; Wang, H.Y. Numerical investigation of slip and fracture instability mechanism of coal rock parting-coal structure (CRCS). J. Struct. Geol. 2019, 118, 265-278. [CrossRef]

30. Tan, Y.L.; Liu, X.S.; Shen, B.; Ning, J.G.; Gu, Q.H. New approaches to testing and evaluating the impact capability of coal seam with hard roof and/or floor in coal mines. Geomech. Eng. 2018, 4, 367-376.

31. Liu, X.S.; Tan, Y.L.; Ning, J.G.; Lu, Y.W.; Gu, Q.H. Mechanical properties and damage constitutive model of coal in coal-rock combined body. Int. J. Rock Mech. Min. Sci. 2018, 110, 140-150. [CrossRef]

32. Bieniawski, Z.T.; Bernede, M.J. Suggested methods for determining the uniaxial compressive strength and deformability of rock materials: Part 1. Suggested method for determination of the uniaxial compressive strength of rock materials. Int. J. Rock Mech. Min. Sci. Geomech. Abstr. 1979, 16, 137-139. [CrossRef]

33. Liu, J.; Wang, E.Y.; Song, D.Z. Effect of rock strength on failure mode and mechanical behavior of composite samples. Arab. J. Geosci. 2015, 8, 4527-4539. [CrossRef]

34. Wang, C.L. Identification of early-warning key point for rockmass instability using acoustic emission/microseismic activity monitoring. Int. J. Rock Mech. Min. Sci. 2014, 147, 171-175. [CrossRef]

35. Zuo, J.P.; Chen, Y.; Cui, F. Investigation on mechanical properties and rock burst tendency of different coal-rock combined bodies. J. Chin. Univ. Min. Tech. 2018, 47, 81-87. (In Chinese)

36. Meng, Q.; Zhang, M.; Han, L.; Pu, H.; Nie, T. Effects of Acoustic Emission and Energy Evolution of Rock Specimens under the Uniaxial Cyclic Loading and Unloading Compression. Rock Mech. Rock Eng. 2016, 49, 3873-3886. [CrossRef]

37. Zhang, J.; Ai, C.; Li, Y.W.; Che, M.G.; Gao, R.; Zeng, J. Energy-Based Brittleness Index and Acoustic Emission Characteristics of Anisotropic Coal under Triaxial Stress Condition. Rock Mech. Rock Eng. 2018, 51, 3343-3360. [CrossRef]

38. Yang, L.; Gao, F.Q.; Wang, X.Q.; Li, J.Z. Study on energy evolution law and failure mechanism of coal-rock combined specimen. J. Chin. Coal Soc. 2019. (In Chinese) [CrossRef]

39. Valery, A.; Vladimir, A. Invariant kinetic approach to the description of a rock Fracture process and induced seismic events. Pure Appl. Geophys. 1996, 2, 367-375. 